\title{
The Turkey Gets the Last Laugh
}

\author{
Richard B. Lush MD
}

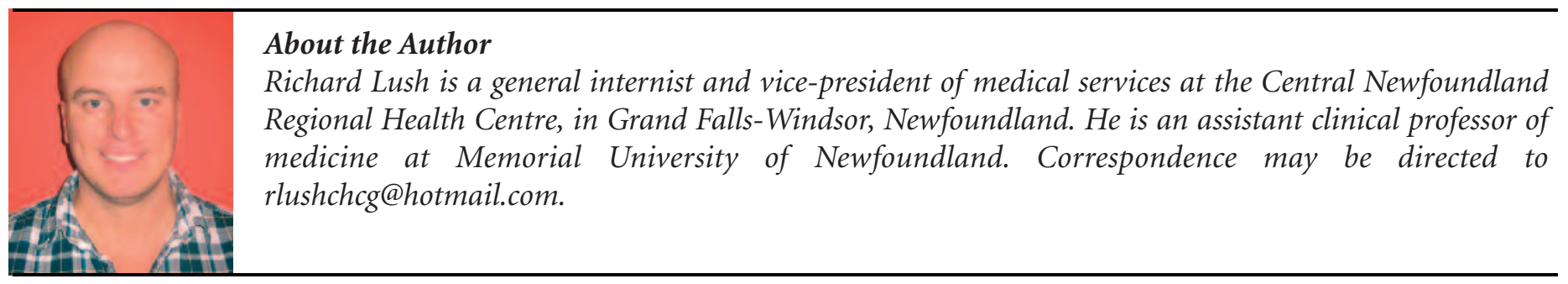

\section{Summary}

A 52-year-old man was referred to a general internal medicine service due to recurrent pneumonia. After physical examination, laboratory tests, and resection to check for malignancy, it was discovered that the patient had a fragment of turkey bone in his lung. This case stresses the importance of considering chronic foreign body aspiration, and remembering that not all lung masses are malignant.

\begin{abstract}
Résumé
Un homme âgé de 52 ans a été adressé à un service de médecine interne générale en raison d'une pneumonie récurrente. À la suite d'un examen physique, de tests de laboratoire et d'une résection destinée à vérifier la présence de malignité, on découvrit que le patient avait un fragment d'os de dinde à l'intérieur d'un poumon. Ce cas fait ressortir l'importance de considérer la possibilité d'aspiration chronique d'un corps étranger et de se rappeler que toutes les masses pulmonaires ne sont pas malignes.
\end{abstract}

\section{Case}

A 52-year-old man was referred to my general internal medicine service due to recurrent pneumonia. He had had several courses of antibiotics for pneumonia over approximately 20 years. During this time, he had developed a chronic cough and progressive shortness of breath on exertion, which he attributed to an 80-pack-year smoking history. He had a previously positive tuberculin skin test in 1995 but could not recollect whether he had received treatment.

His past medical history included type 2 diabetes mellitus, hypertension, and hypercholesterolemia. He was taking rosuvastatin $10 \mathrm{mg}$ daily, metformin $500 \mathrm{mg}$ twice daily, candesartan $8 \mathrm{mg}$ daily, and celecoxib $200 \mathrm{mg}$ twice daily. His mother died at age 42 from lung cancer.

The physical examination revealed decreased air entry bilaterally. There was no clubbing or hoarseness, and his examination was otherwise normal.

A computed tomography scan of the chest (Figure 1) revealed a $1.5 \mathrm{~cm}$ endobronchial mass within the proximal right lower lobe bronchus, associated with wall thickening, bronchiectasis, and post-obstructive pneumonitis.

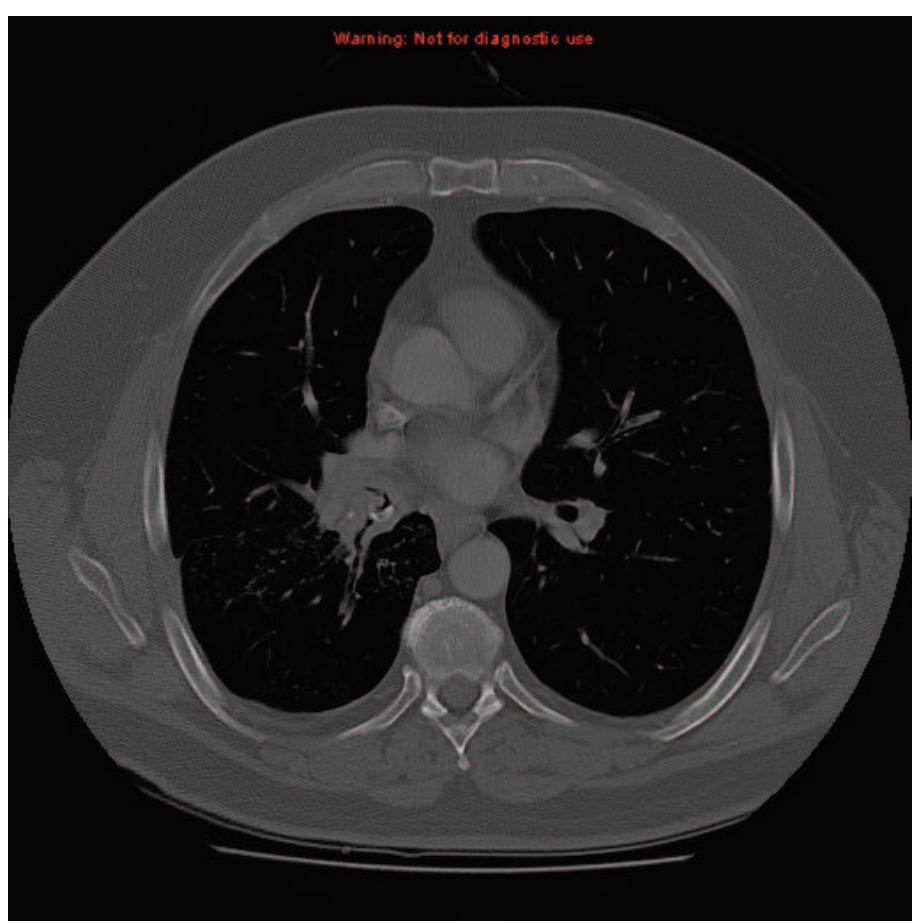

Figure 1. Computed tomography scan of the chest revealing a $1.5 \mathrm{~cm}$ endobronchial mass within the proximal right lower lobe bronchus. 


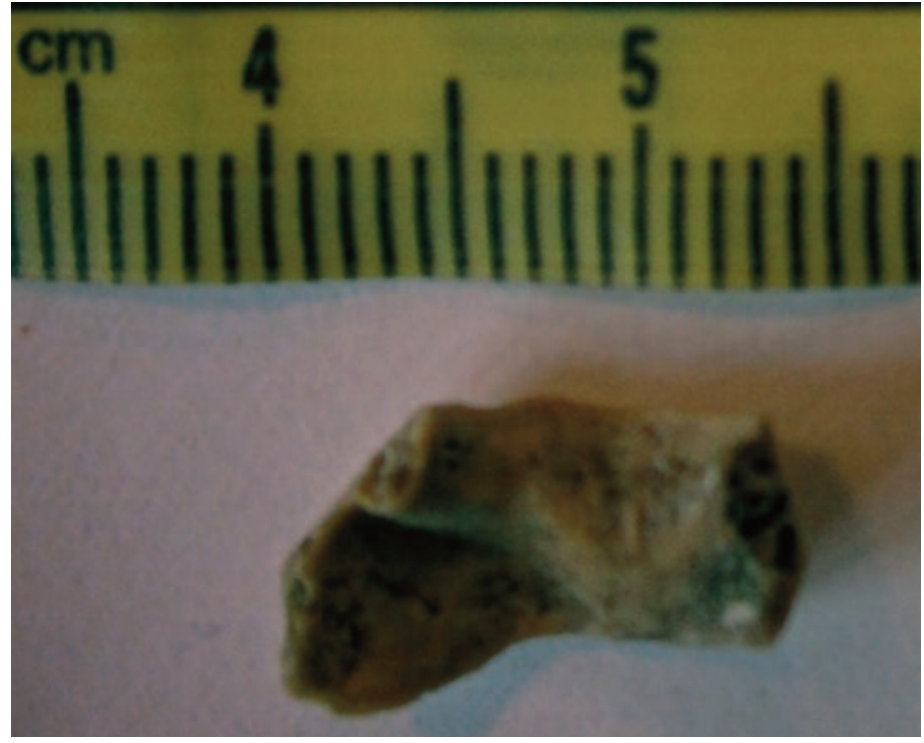

Figure 2. Tan foreign body located in the specimen - a turkey bone.

The patient received video bronchoscopy. His right lower and middle lobe bronchi were occluded. There was also irregular mucosa with polypoid lesions. This was very suggestive of malignancy; hence, washings, brushings, and biopsies were performed. Results revealed only reactive tissue and squamous metaplasia. Therefore, a repeat diagnostic bronchoscopy was performed, again with negative results. Convinced of malignancy, I consulted an interventional respirologist.

The patient underwent a third bronchoscopy, along with endobronchial sonography. This revealed minimally enlarged lymph nodes. The occluded right lower lobe was then opened using air jets and saline, and the bronchoscope was advanced beyond the occlusion. Here, numerous biopsies and washings were performed, and copious pus extruded from the area. Pathology again showed only squamous metaplasia and no malignancy. A test for tuberculosis was negative.

Next, this patient was referred to the Thoracic Surgery Department for yet a fourth bronchoscopy. Biopsies were again negative. Pulmonary function tests revealed moderate obstructive lung disease with a forced expiratory volume in 1 second $\left(\mathrm{FEV}_{1}\right)$ of $2.22 \mathrm{~L}$. A decision was made to resect the right lower lobe, as all felt there had to be a malignancy. Operative pathology was negative for malignancy. However, a tan foreign body measuring $1 \times 0.5 \times 0.3 \mathrm{~cm}$ was located in the specimen (Figure 2) ... that turned out to be a turkey bone!

On further questioning, the patient recalled a camping trip approximately 29 years prior. After consuming copious alcohol, and while drinking turkey-neck soup, he had had a dramatic coughing/choking attack. It resolved, and he had forgotten about it until now. In hindsight, his symptoms had started from that point.

Since surgery, he reports feeling the best he has felt in years. His dyspnea has improved, and he has had no further respiratory infections. He has also successfully quit smoking.

\section{Discussion}

Foreign body aspiration is more common in the pediatric and geriatric populations. ${ }^{1}$ There are several risk factors that predispose adults with a normal swallowing reflex to foreign body aspiration. These include excessive alcohol consumption, neurological dysfunction, trauma (with an altered level of consciousness), seizures, and general anesthesia. ${ }^{2}$ The majority of foreign bodies in adults are of organic material, but can include bone, tooth material, pen caps, swabs, and pieces of plastic. ${ }^{3}$

Adults typically have long asymptomatic intervals, ranging from months to years. Often, patients are treated for an alternative diagnosis such as bronchitis, asthma, pneumonia, and malignancy. Typically, adults present with chronic cough and dyspnea. ${ }^{2}$

For patients with a long asymptomatic interval, diagnosis is usually impeded by the cellular response to the foreign body. This response usually results in edema, ulceration, and the formation of granulation tissue. As a result, radiological images and bronchoscopic analysis can mimic a mass-like lesion, especially as the foreign body can be lost in the granulation tissue. ${ }^{2}$

General internists are taught that patients who present with recurrent pneumonias should be investigated for underlying bronchogenic carcinoma. This case stresses the importance of considering chronic foreign body aspiration, and remembering that not all lung masses are malignant. Moreover, patients can harbour foreign bodies for years with minimal clinical sequelae. Although difficult to diagnose, treatment is rewarding to both the patient and physician alike. Finally, be careful when drinking your turkey neck soup!

\section{Acknowledgement}

I send special thanks to Dr. Joseph Lockyer, who assisted in this case and manuscript review.

\section{References}

1. Qureshi A, Behzadi A. Foreign body aspiration in an adult. Can J Surg 2008;51(3):E69-70.

2. Patel S, Kazerooni El. Case 31; foreign body aspiration - chicken vertebra. Radiology 2001;218:523-5.

3. Baharbo F, Veyckeman F, Francis C, et al. Tracheobrochial foreign bodies; presentation and management in children and adults. Chest 1999;115:1357-62. 